\title{
Isolation of bacteriophages from must and wine for the elimination of contaminating bacteria as an alternative to the use of sulfurous
}

\author{
G. Cordero-Bueso ${ }^{1, \text { a }}$, J. Moraga ${ }^{1,2}$, M. Rios-Carrasco ${ }^{1}$, M. Ruiz-Muñoz ${ }^{1}$ y J. Manuel Cantoral ${ }^{1}$ \\ 1 Áreade Microbiología, Departamentode Biomedicina, Biotecnologíay Salud Pública, Universidad de Cádiz, España \\ ${ }^{2}$ Departamento de Química Orgánica, Universidad de Cádiz, España
}

\begin{abstract}
Acetic and some lactic acid bacteria are the main reason for the loss of quality of musts and wines, giving rise to defects such as "vinegary", "chopped" or preventing alcoholic and / or malolactic fermentation. The solution to this problem consists in the application of authorized bactericidal agents, such as sulfurous. The aim of this work is to isolate bacteriophages from musts and wines of different grape varieties, able to eliminate lactic and acetic acid bacteria spoilages. Musts obtained from grape-berries of Vitis vinifera cv. Chardonnay and Moscatel and a red wine made with the Tintilla de Rota variety were used to isolate bacteriophages. It were isolated by classical virology methods and identified by electron microscopy. Host bacteria used in the study were the lactic acid bacteria of the species Lactobacillus hilgardii, L. plantarum and Oenococcus oeni and the acetic bacteria Acetobacter aceti. A comparative study was performed on musts and wines, previously inoculated with bacteria, by phage titration and $\mathrm{SO}_{2}$ addition to study the effectiveness of bacteriophages against bacteria. Bacteriophages were obtained from all musts and wine, belonging to the order of Caudovirals and Tectivirals. The comparative study showed that a cocktail of bacteriophages at low concentration is as effective as sulfur.
\end{abstract}

\section{Introducción}

El anhídrido sulfuroso es el compuesto antimicrobiano más utilizado en vinificación por su eficacia y su bajo coste, siendo útil para un amplio espectro de microorganismos. A pesar de ser activo frente a bacterias y levaduras, se caracteriza por combinarse con piruvato, 2-cetoglutarato, entre otros, producidos por las levaduras en fermentación, de forma que no es perjudicial para las mismas y actuando exclusivamente sobre bacterias. La ventaja principal de este hecho es que Saccharomyces cerevisiae, levadura principal de fermentación, no se ve afectada y puede realizarla con normalidad.

La cantidad de sulfuroso añadida al vino se va reponiendo a medida que se agote el $\mathrm{SO}_{2}$ libre, y su eficacia viene dada por cómo se combina con los compuestos presentes en los distintos tipos de vino y por el pH del mismo. Cuanto más ácido sea, más activo será el $\mathrm{SO}_{2}$ libre. La dosis inicial utilizada dependerá de factores como el grado de madurez de la uva, el estado sanitario de la vendimia y su temperatura, y principalmente, del tipo de vino que se quiera obtener. Debido a la gran diversidad de vinos existente, no hay una dosis preestablecida, sino que cada enólogo la ajusta según las materias primas, tecnología y productos de los que disponga.

Según el Reglamento (UE) n 53/2011 de la Comisión, de 21 de enero de 2011 por el que se modifica el Reglamento (CE) $n^{\circ} 606 / 2009$, la Comisión Europea establece una dosis de $\mathrm{SO}_{2}$ total $(\mathrm{mg} / \mathrm{L})$ autorizado según el tipo de vino. Sin embargo, cada vez son más las personas

a e-mail: gustavo.cordero@uca.es alérgicas o sensibles a este compuesto y en consecuencia, la Comisión Europea ha propuesto limitar su uso, hasta la completa prohibición. Este hecho supone un problema para el sector enológico, ya que no existen alternativas reales y puede suponer pérdidas de calidad importantes en el producto final, debido a no poder controlar la proliferación de microorganismos perjudiciales para el vino. Las bacterias acéticas y algunas lácticas son las principales responsables de la pérdida de calidad de mostos y vinos, dando lugar a defectos como el "avinagrado", "picado" o impidiendo la fermentación alcohólica y/o maloláctica [1].

Desde la comunidad científica se han propuesto algunas alternativas al anhídrido sulfuroso, tales como nuevos conservantes y tecnologías mecánicas innovadoras que por supuesto son inofensivas para la salud, y que pueden reemplazar o reducir la concentración de sulfuroso [2]. Pero para ello, deben garantizar la estabilidad microbiológica de los vinos, protegerlos contra la oxidación y mantener las características de calidad del producto final. Sin embargo, los tratamientos químicos y mecánicos propuestos como alternativa al sulfuroso alteran en gran parte las características organolépticas del vino.

Los bacteriófagos, también conocidos como fagos, son virus que infectan y lisan específicamente a bacterias. En los últimos años, se han propuesto como alternativa al uso de antibióticos en salud animal, como biopreservadores de alimentos y como herramienta para detectar bacterias patógenas en cadenas alimentarias [3]. El hecho de ser inocuos para células humanas y específicos en su rango de hospedador, convierte a los 
bacteriófagos en una alternativa innovadora y segura a productos químicos tradicionales empleados en la industria alimentaria, los cuales generan, y cada vez con más frecuencia, alergias e intolerancias a los productos que los contienen en las personas. Por otro lado, la producción de estos agentes químicos, entre los que se incluyen, por ejemplo, pesticidas o herbicidas, crea un impacto medioambiental en los ecosistemas, además de un impacto socioeconómico, debido a que la población tiende a consumir productos cada vez más naturales, con menos componentes alérgenos y aditivos.

En este trabajo se busca una alternativa a la adición de anhídrido sulfuroso al vino y se estudia la posibilidad de que haya bacteriófagos presentes de forma natural en la uva y en su mosto, así como en el vino, los cuales sean capaces de evitar el crecimiento de bacterias lácticas y acéticas responsables de la pérdida de calidad de este producto.

\section{Materiales y métodos}

\subsection{Cepas bacterianas}

Se seleccionaron cepas de bacterias más comunes en la enología. Las cepas tanto de bacterias lácticas como acéticas fueron obtenidas de la Colección Española de Cultivos Tipo (CECT). Las cepas de bacterias lácticas utilizadas fueron Lactobacillus hilgardii (CECT 4786), Lactobacillus plantarum (CECT 7484) y Oenococcus oeni (CECT 4742). Respecto a cepas de bacterias acética la cepa seleccionada fue Acetobacter aceti (CECT 473).

\subsection{Medios de cultivo}

Los medios de cultivo utilizados en el estudio fueron aquéllos específicos para el correcto crecimiento de las diferentes cepas bacterianas. Para las bacterias lácticas del género Lactobacillus se utilizó el Medio MRS líquido/agar (Peptona $1 \% \mathrm{p} / \mathrm{v}$, extracto de carne $1 \% \mathrm{p} / \mathrm{v}$, extracto de levadura $0.5 \mathrm{p} / \mathrm{v}$, glucosa $2 \% \mathrm{p} / \mathrm{v}$, citrato de amonio 0.2 $\mathrm{p} / \mathrm{v}$, acetato de sodio $5 \% \mathrm{p} / \mathrm{v}, \mathrm{MgSO} 4 \cdot 7 \mathrm{H} 2 \mathrm{O} 0.2 \% \mathrm{p} / \mathrm{v}$, $\mathrm{MnSO} 4 \cdot \mathrm{H} 2 \mathrm{O} 0.2 \% \mathrm{p} / \mathrm{v}$, K2HPO4 $2.00 \mathrm{~g}$ disueltos en un litro de agua destilada ( $\mathrm{pH}$ a 6.2-6.5). La cepa de $O$. oeni se cultivó en medio MLO (Triptona $1 \% \mathrm{p} / \mathrm{v}$, extracto de levadura $0.5 \% \mathrm{p} / \mathrm{v}$, glucosa $1 \% \mathrm{p} / \mathrm{v}$, fructosa $0.5 \% \mathrm{p} / \mathrm{v}$, MgSO4. $7 \mathrm{H} 2 \mathrm{O} 0.2 \% \mathrm{p} / \mathrm{v}, \mathrm{MnSO} 4 \cdot \mathrm{H} 2 \mathrm{O} 0,05 \% \mathrm{p} / \mathrm{v}$, citrato de diamonio $0.35 \% \mathrm{p} / \mathrm{v}$, hidrocloruro de L-Cisteina $0.5 \%$ $\mathrm{p} / \mathrm{v}$, zumo de tomate filtrado $100 \mathrm{ml}$, Tween $801 \mathrm{ml}$ en $900 \mathrm{ml}$ de agua destilada, $\mathrm{pH}$ 4.8).

En el caso de la bacteria acética se utilizaron dos medios de cultivo, medio GYC (glucosa $2 \%$ p/v, extracto de levadura $1 \% \mathrm{p} / \mathrm{v}, \mathrm{CaCO} 32 \% \mathrm{p} / \mathrm{v}$ en $1 \mathrm{~L}$ agua destilada, $\mathrm{pH}$ 6.8) y medio Mueller-Hinton (Extracto de carne $0.2 \%$ $\mathrm{p} / \mathrm{v}$, hidrolizado de caseína $1.75 \%$ p/v, almidón $0.15 \%$ p/v, agar $1.7 \% \mathrm{p} / \mathrm{v}$ en $1 \mathrm{~L}$ de agua destilada, $\mathrm{pH}$ a $7.3 \pm 0.1$ ).

\subsection{Titulación}

La presencia de fagos se detectó mediante la técnica clásica de agar de doble capa (double-layer agar technique) descrita por Sambrook [4]. Para ello se centrifugó un eurotubo con $25 \mathrm{ml}$ de mosto o vino a $5000 \mathrm{rpm}$ durante 10 minutos y se filtró con un filtro $0.2 \mu \mathrm{m}$ (Millipore). Se realizaron ensayos para cada una de las bacterias en mostos y vinos de tres variedades de uvas diferentes; Vitis vinifera ssp. vinifera cv. Tintilla de Rota, cv. Moscatel, cv. Chardonnay.

Se prepararon diluciones seriadas (desde $10^{-1}$ a $10^{-7}$ ) de la muestra del bacteriófago en PBS $1 \mathrm{X}$ estéril y se añadieron $500 \mu \mathrm{l}$ del cultivo bacteriano a cada dilución, incluyendo un control sin añadir el bacteriófago. Se incubaron 10 minutos a la temperatura de crecimiento de cada bacteria $\left(30^{\circ} \mathrm{C} \mathrm{L}\right.$. hilgardii, L. plantarum, $26^{\circ} \mathrm{C} \mathrm{O}$. oeni y $28^{\circ} \mathrm{C}$ A. aceti). A continuación, se prepararon tubos estériles con $6 \mathrm{ml}$ de agar de cobertura, se les adicionó el volumen completo de cada solución fago- bacteria y se mezcló suavemente. El contenido de los tubos se vertió sobre placas Petri con agar nutritivo, evitando la aparición de burbujas, y se dejaron secar 10 minutos en la campana flujo laminar. Las placas se incubaron invertidas a la temperatura correspondiente al cultivo bacteriano durante 24 horas para bacterias lácticas y 72 horas para bacterias acéticas.

\subsection{Aislamiento de bacteriófagos}

Los bacteriófagos presentes en el mosto se aislaron a partir de las placas de lisis formadas en las titulaciones. Se recortaron tacos de agar con un bisturí estéril en ángulo recto y se colocaron en un tubo Eppendorf conteniendo $1 \mathrm{ml}$ de PBS 1X. Seguidamente se agregaron 3 gotas de cloroformo y se agitaron los tubos durante 1 minuto con la ayuda de un vórtex. Se centrifugaron a $4{ }^{\circ} \mathrm{C}$ a $5300 \mathrm{rpm}$ y se filtró el sobrenadante con un filtro de $0.2 \mu \mathrm{m}$ (Millipore). Se repitió el mismo procedimiento para cada uno los bacteriófagos obtenidos en cada mosto o vino. Los tubos se conservaron a $4{ }^{\circ} \mathrm{C}$ para análisis posteriores.

Se comprobó el éxito del aislamiento mediante una segunda titulación siguiendo el protocolo mencionado en el apartado anterior.

\subsection{Caracterización de bacteriófagos}

\subsubsection{Extracción de $A D N$}

Se enriqueció un cultivo de bacteria huésped en fase exponencial con $100 \mu \mathrm{l}$ del bacteriófago. Pasadas 16 horas a la temperatura de crecimiento de la bacteria, se adicionó cloroformo y los cultivos se centrifugaron, se seleccionó el sobrenadante y se filtró con un filtro de $0,20 \mu \mathrm{m}$.

La extracción de ADN de los fagos se llevó a cabo mediante el protocolo descrito por Sambrook y Russel (2001), con algunas modificaciones. Se tomaron $400 \mu \mathrm{l}$ de la suspensión de fago, se añadieron $20 \mu \mathrm{l}$ de EDTA $(0,5 \mathrm{M}$ Ph:8), $50 \mu \mathrm{l}$ de SDS al $10 \%$ y $5 \mu \mathrm{l}$ de proteinasa $\mathrm{K}$ y se dejó incubar la muestra. Se añadieron $400 \mu \mathrm{l}$ de fenol saturado en Tris- $\mathrm{HCl} 0,5 \mathrm{M}$ y se centrifugó a $13000 \mathrm{rpm}$ durante 4 minutos. Se recogió la fase acuosa y se añadieron $200 \mu \mathrm{l}$ de fenol saturado en Tris- $\mathrm{HCl}$ y $200 \mu \mathrm{l}$ de fenol:cloroformo:alcohol isoamil (25:24:1). Se mezcló y centrifugó a 13000 durante 4 minutos. La fase acuosa se traspasó a un tubo nuevo, se añadieron $400 \mu \mathrm{l}$ de fenol:cloroformo:alcohol isoamil y se centrifugó a $12000 \mathrm{rpm}$ durante 4 minutos. La fase acuosa vuelve a transferirse a otro tubo y se añaden $200 \mu \mathrm{l}$ de acetato potásico $(3 \mathrm{Mph}=7)$ y $600 \mu \mathrm{l}$ de isopropanol. Se centrifugó a $12000 \mathrm{rpm}$ durante 10 minutos. El sobrenadante fue desechado y el pellet se resuspendió en $200 \mu \mathrm{l}$ de etanol $70 \%$ frío. Se centrifugó a $13000 \mathrm{rpm}$ durante 4 minutos y se descartó el etanol, 
para secar el pellet a $45^{\circ} \mathrm{C}$ durante 20 minutos en un concentrador Speed-Vac (Eppendorff). Finalmente, el pellet se resuspendió en $50 \mu \mathrm{l}$ de TE 1x. Para comprobar la concentración de ADN extraído se comprobó con un Nanodrop (Thermofisher Scientific), a una longitud de onda de 260/280 nm.

Los resultados fueron visualizados mediante electroforesis en un gel de agarosa al $0.7 \%$ en tampón TAE $1 \mathrm{X}$. La electroforesis se ejecutó a $100 \mathrm{~V}$ durante 60 minutos. El gel de agarosa se reveló en una solución de Bromuro de Etidio $5 \mu \mathrm{g} / \mathrm{mL}$. El marcador utilizado fue el fago lambda digerido con la enzima HindIII.

\subsubsection{Campo pulsante (PFGE)}

Para llevar a cabo el análisis por electroforesis en campo pulsante (PFGE), $1 \mu \mathrm{g}$ de las muestras de $\mathrm{ADN}$ viral sin digerir se calentaron a $60^{\circ} \mathrm{C}$ durante 5 minutos para desnaturalizar los extremos cohesivos (cos), se enfriaron en hielo durante 5 minutos y rápidamente se añadieron en una solución de agarosa de bajo punto de fusión (cf: $0.6 \%$, Pronadisa), seguidamente se cargó en un gel de agarosa certificada (Pulsefield agarose, Biorad) al 1\% en buffer 0,5X TBE (Tris 0.89M, EDTA 0.02M, ácido bórico $0.89 \mathrm{M}$ ) para llevarlo a electroforesis. El PFGE se llevó a cabo en un sistema CHEF-DRIII SYS220/240 (Biorad). Las condiciones de corrido fueron un pulso inicial 0.1 segundos y un pulso final 8 segundos. El tiempo de electroforesis fueron 15 horas aplicando un campo eléctrico de $0.6 \mathrm{Vcm}^{-1}$. El sistema trabajó a una temperatura de $14{ }^{\circ} \mathrm{C}$ y un ángulo de $120^{\circ}$.

Pasado el tiempo de electroforesis, el gel se tiñó con bromuro de etidio $5 \mu \mathrm{g} / \mathrm{mL}$ y se visualizó con un equipo de imagen con transiluminador UV (Biorad). El tamaño del genoma se determinó utilizando como referencia el genoma digerido del fago Lambda con la enzima de restricción HindIII.

\subsection{Microscopía electrónica de transmisión}

La observación de los bacteriófagos objeto de estudio se llevaron a cabo en un microscopio electrónico de transmisión termoiónico (MET) JEOL 2100. La preparación de las muestras consistión en añadir $8 \mu \mathrm{l}$ de cada fago aislado y purificado sobre una rejilla de cobre de $300 \mathrm{MESH}$ tratada con carbono. A continuación se adicionó una solución de ácido tungstofosfórico al $2 \%(\mathrm{pH} 8.1)$ y se dejó reaccionar durante 10 minutos, pasado ese tiempo se secó con paper de filtro y se dejó secar a temperatura ambiente y se almacenaron hasta su observación en el MET.

\subsection{Efecto inhibitorio de bacteriófagos frente al anhídrido sulfuroso}

Se hizo una prueba de la eficacia de los bacteriófagos aislados frente al sulfuroso. Los ensayos se realizaron inoculando las diferentes bacterias en los diferentes mostos o vinos en una placa de 96 pocillo y con una distribución como se muestra en la Fig. 1. La concentración de bacteria se mantuvo constante $\left(10^{6}\right.$ células $\left./ \mathrm{mL}\right)$, mientras que los bacteriófagos se diluyeron entre $10^{-1}$ y $10^{-8} \mathrm{UPF} / \mathrm{mL}$. Las concentraciones de sulfuroso variaron entre $450 \mathrm{mg} / \mathrm{L}$ y $100 \mathrm{mg} / \mathrm{L}$, realizadas a partir de una disolución madre de metabisulfito de sodio en agua a una concentración

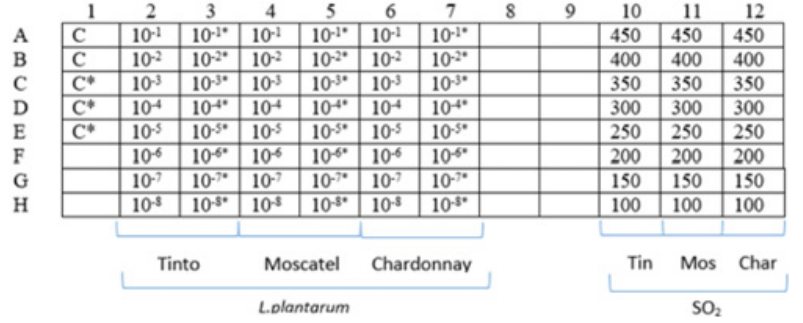

Figura 1. Plantilla de la disposición de las muestras de los diferentes bacteriófagos y sulfuroso a diferente concentraciones en cultivos de la bacteria L. plantarum en una placa de 96 pocillos (Tin: Tinto, Mos: Moscatel, Char: Chardonnay).

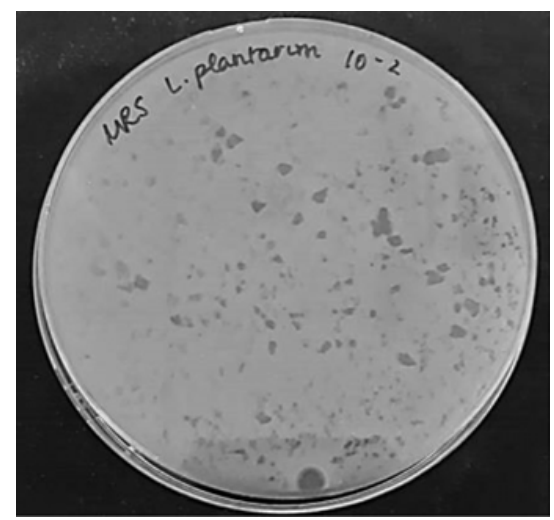

Figura 2. Detalle de placas de lisis producidas por bacteriófagos procedentes de vino tinto en una placa con L. plantarum.

de $500 \mathrm{mg} / \mathrm{L}$. Se eligió este rango de concentraciones de acuerdo al Reglamento (UE) n 53/2011 de la Comisión, de 21 de enero de 2011 por el que se modifica el Reglamento (CE) n $n^{\circ}$ 606/2009, que fija determinadas disposiciones de aplicación del Reglamento (CE) $\mathrm{n}^{\circ}$ 479/2008 del Consejo en lo relativo a las categorías de productos vitícolas, las prácticas enológicas y las restricciones aplicables.

\section{Resultados y discusión}

\subsection{Titulaciones}

Se observaron placas de lisis en las titulaciones para L.plantarum de muestras filtradas de tinto, Moscatel y Chardonnay, para L.hilgardii de tinto y para O.oeni de tinto, Moscatel y Chardonnay (Fig. 2). Las titulaciones de Acetobacter aceti no mostraron placas de lisis, tanto para muestras de vinagre comercial como para vino tinto y mosto de Moscatel y Chardonnay en los dos medios de cultivo utilizados (GYC y MH). Las placas se confirmaron tras una segunda titulación realizada con las muestras de aislados fágicos procedentes de la primera titulación.

\subsection{Aislamiento e identificación de bacteriófagos}

Se aislaron un total de 7 bacteriófagos que fueron nombrados de acuerdo a las muestras que fueron aislados. Los aislados de vino tinto sobre L.plantarum se denominó Tin1Lp, sobre L.hilgardii Tin $1 L h$ y sobre O. oeni Tin $1 O$ o. Los aislados de mosto Moscatel se denominaron Mos $1 L p$ en L. plantarum y Mos1Oo, en O. oeni. Los aislados 


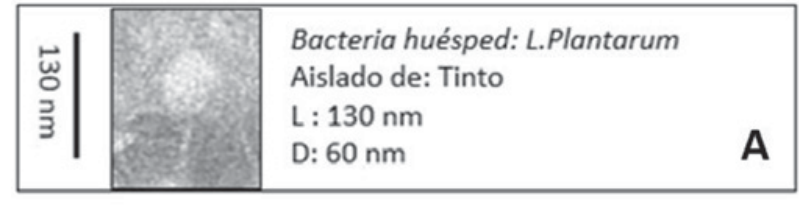

\begin{tabular}{|l|l|l|}
\hline \multirow{2}{*}{} & & $\begin{array}{l}\text { Bacteria huésped: O.Oeni } \\
\text { Aislado de: Tinto }\end{array}$ \\
3 & & $\begin{array}{l}\text { L: } 100 \mathrm{~nm} \\
\text { D: } 50 \mathrm{~nm}\end{array}$ \\
\hline
\end{tabular}

Figura 3. Morfologías observadas para los dos órdenes de bacteriófagos Caudovirales (A) y Tectivirales (B) aislados e identificados por microscopía electrónica de transmisión.

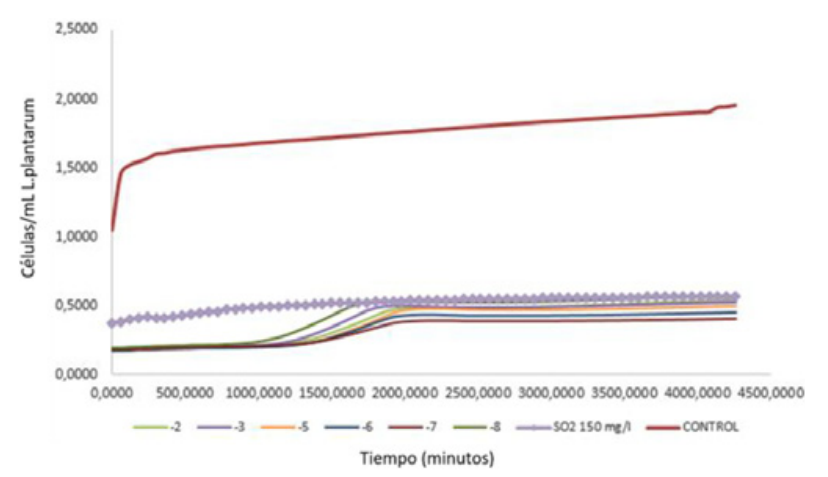

Figura 4. Cinética de crecimiento de L.plantarum frente a un tratamiento con $\mathrm{SO}_{2}$ a $150 \mathrm{mg} / \mathrm{L}$ y 6 bacteriófagos aislados en vino tinto.

de Chardonnay se denotaron como Char1Lp sobreL. plantarum y Char1 Oo sobre O. oeni.

Posteriormente se analizó la morfología de los fagos aislados por microscopía electrónica de transmisión (Fig. 3) y se clasificaron taxonómicamente de acuerdo a las reglas propuestas por el International Committee on Taxonomy of Viruses [5].

Los fagos que infectan a bacterias lácticas pertenecieron al orden Caudovirales. Los fagos Tin $1 L p$ y Tin $1 L h$ pertenecen a la familia Siphoviridae (fagos de cola larga no contráctil), los fagos Mos $1 L p$ y CharLp pertenecen a la familia Myoviridae (fagos con cola contráctil) y aquéllos que infectaron a $O$. oeni pertenecen a la familia Tectiviridae (fagos con visícula lipídica y pseudo-cola).
Adicionalmente, se realizó la extracción de ADN de los bacteriófagos y se cuantificaron en un nanodrop obteniéndose cantidades altas de material genético en todos los casos, entre $100-1000 \mathrm{ng} / \mu \mathrm{L}$. Este material genético se embebió en un plug de agarosa de baja resolución y se sometió a electroforesis por campo pulsante. Donde se comprobó que los bacteriofagos pertenecientes al orden caudovirales presentaron un genoma de tamaños entre los 500 y 1000 pb, mientras que en los tectovirus fue de $1500 \mathrm{pb}$.

\subsection{Efecto inhibitorio de los bacteriófagos}

Para determinar la eficacia de cada bacteriófago frente a las tres bacterias estudiadas, se realizó una cinética, en un lector multiplacas, incubando los fagos a diferentes concentraciones junto a un cultivo de $10^{6}$ cells $/ \mathrm{mL}$ de las distintas bacterias. Además se utilizó un control dónde solo había bacterias. También se llevó a cabo el ensayo utilizando anhídrido sulfuroso a diferentes concetraciones (400-100 ppm) y se comparó la eficacia de inhibición de los bacteriófagos frente a las bacterias. En todos los casos una concentración de fagos de $10^{7} \mathrm{UFP} / \mathrm{mL}$ fue suficiente para inhibir el crecimiento de la bacteria en comparación con una dosis de $\mathrm{SO}_{2}$ de $150 \mathrm{mg} / \mathrm{L}$ (Fig. 4).

\section{Conclusiones}

El estudio comparativo mostró que un cóctel de bacteriófagos a baja concentración es tan efectivo como el sulfuroso. Este trabajo podría abrir nuevos frentes para la reducción en la utilización del sulfuroso y que el consumidor identifique el producto final como seguro y saludable. Los bacteriófagos se pueden postular como una alternativa viable a los productos químicos.

\section{Referencias}

[1] I.Y. Sengun, Acetic Acid Bacteria (CRC Press, 2017)

[2] E. Guerrero, Cantos-Villar, Trends Food Sci. Technol. 42, 27 (2015)

[3] J.M.K.J.K. Premarathne, T.Y. Thung, C.Y. New, J.T.Y. Huat, D.F. Basri, Y. Rukayadi, Y. Nakaguchi, M. Nishibuchi, R. Son, Int. Food Res. J 24, 2 (2017)

[4] J. Sambrook, D.W. Russell, Molecular cloning: A laboratory manual (Cold Spring Harbor Laboratory Press, New York, 2001)

[5] H.W. Ackermann, Arch. Virol. 146, 843 (2001) 